\title{
ON THE BIOLOGY OF GLOSSUS HUMANUS (L.) (ISOCARDIA COR LAM.)
}

\author{
By G. Owen \\ The Marine Station, Millport, and the Department of Zoology, \\ University of Glasgow
}

(Text-figs. I-9)

Glossus humanus (L.), the only living representative of the genus, is a large eulamellibranch living in Western European seas and the Mediterranean. Nicol (I95I) has reviewed the geological history and geographical distribution of the species, but little is known of its structure and habitat. Specimens were obtained from the Clyde Sea Area by use of an Agassiz trawl in depths of over $50 \mathrm{~m}$. in the channel between the islands of Arran and Bute. Work on these specimens was carried out at the Marine Station, Millport, and the Zoology Department of the University of Glasgow.

I wish to express my gratitude to Prof. C. M. Yonge, F.R.S., for his encouragement and guidance during the course of this work and also to the Director and Staff of the Millport Laboratory for assistance in many ways. I am indebted to Dr Vera Warrender for the drawing of the shell reproduced in Fig. I. Acknowledgement is also due to the Development Commission for financial assistance.

\section{THE SHELL}

The shell in G. humanus is equivalve, inequilateral and markedly globular with the umbones spirally enrolled and directed anteriorly. Many of the generic and specific names that have been applied to this species result from the resemblance of the shell, when viewed anteriorly, to the mammalian heart (Fig. I).

In the Lamellibranchia, the direction of growth at any region of the valve margins may be resolved into: (a) a radial component radiating from the umbone and acting in the plane of the generating curve; $(b)$ a transverse component acting at right angles to the plane of the generating curve; (c) a tangential component acting tangentially to, and in the plane of, the generating curve (Owen, I952). The radial component is always present and affects the form of both valves. In the primitive bivalve, the normal axis was probably a plano-spiral and the form of the shell the resultant of radial and transverse components. In G. humanus, however, the normal axis (Fig. 2, NA) is a turbinate spiral, indicating that the form of the shell is the resultant of radial $(\mathrm{R})$, transverse and tangential $(\mathrm{T})$ components. 
In genera where the tangential component is absent (e.g. Tellina), the cardinal teeth radiate across the hinge plate, increasing slowly in all dimensions with growth. But in G. humanus, the mantle isthmus (Owen, Trueman \& Yonge, I953) is continuously displaced posteriorly due to the effect of the tangential component on the mantle edge (Fig. 2). As a consequence, the cardinal teeth of both valves are long and extend almost parallel to the sides of the hinge plate (CC, ACR and PCR). The anterior lateral teeth are much reduced or absent (Lamy, I920) while the posterior lateral teeth (PLR) are elongate, since in this region the tangential component, by displacing the secreting surfaces posteriorly, reinforces the effect of the radial component.

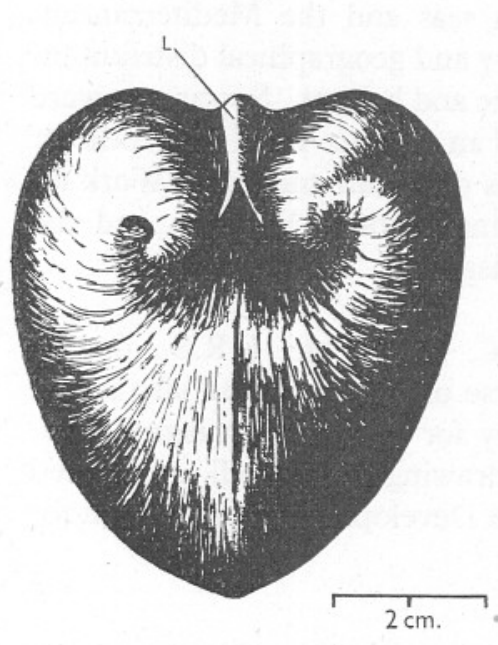

Fig. I.

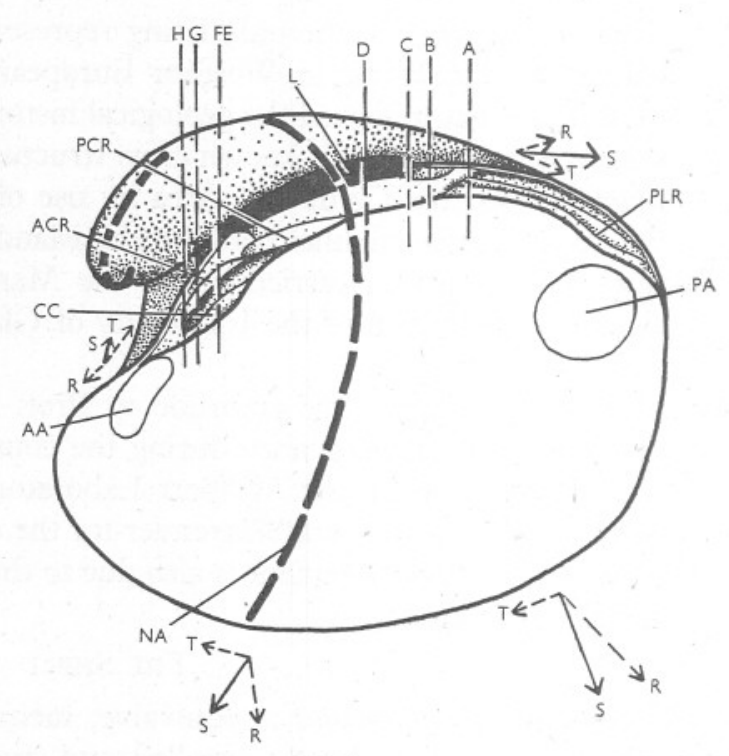

Fig. 2.

Fig. I. G. humanus, the shell viewed anteriorly. L, ligament.

Fig. 2. G. humanus, the right valve showing the dentition of the hinge plate. AA, anterior adductor muscle scar; ACR, right anterior cardinal tooth; CC, central cardinal tooth; L, ligament; NA, normal axis; PA, posterior adductor muscle scar; PCR, right posterior cardinal tooth; PLR, right posterior lateral tooth; $\mathrm{R}$, radial component; $\mathrm{s}$, direction of growth at the mantle/shell margin; $\mathrm{T}$, tangential component. The letters $\mathrm{A}-\mathrm{H}$ refer to positions of transverse sections drawn in Fig. 3. Sections $3 \mathrm{E}$ and $\mathrm{F}$ are represented by a single line.

The description of the hinge teeth given by Jeffreys (I863) is confusing, for the dentition of the right valve is described as that of the left and vice versa.

The tangential component also affects the anterior region of the external opisthodetic ligament (Owen, 1953). When there is no tangential component affecting the form of the valves, as in Glycymeris, growth of the mantle/shell (Yonge, I953) anterior to the umbones takes place anteriorly, i.e. away from 
the umbones. In Glossus humanus, however, as shown in Fig. 2, the radial (R) and tangential $(\mathrm{T})$ components anterior to the umbones are opposed. Owing to the greater magnitude of the tangential component at this region, growth of the mantle/shell margin is in a posterior direction between the umbones, causing them to be increasingly separated as growth proceeds. This separation of the umbones results in a progressive splitting of the anterior region of the ligament, the split portions extending under the spirally twisted umbones (Fig. I, L).

Covering the external surface of the shell is a reddish brown periostracum which, except at the anterior ventral to the umbones, is produced into numerous radiating rows of small bristle-like projections ('cilia' of Forbes \& Hanley, 1853). The shell is thin and remarkably light in weight, the smaller specimens being extremely fragile. Bøggild (1930) has described the detailed structure of the layers composing the shell valves. Internally the valves have a smooth porcellaneous appearance while the pallial line is poorly defined. The posterior adductor muscle scar (Fig. 2, PA) is larger than the deeper anterior scar (AA). This deeper insertion of the anterior adductor muscle is possibly due to the lower rate of growth of the anterior region of the shell. The rate of migration of the anterior adductor muscle is, therefore, considerably less than that of the posterior adductor, while the rate of deposition of the inner layers of the shell is presumably equal for both regions.

\section{The Ligament and Mantle Isthmus}

In describing the structure of the ligament in $G$. humanus the nomenclature suggested by Owen et al. (I953) has been used. The relationships of the mantle, ligament and valves are shown in Fig. $3(\mathrm{~A}-\mathrm{H})$. These figures form a series taken from posterior of the ligament to a region near the umbones as shown in Fig. 2. The interpretation of the structure and formation of the ligament will be more readily understood by comparing the sections shown in Fig. 3 with the diagrammatic representation of the ligament shown in Fig. 4 .

Fig. $3 \mathrm{~A}$ represents a section through the valves and mantle between the siphons and the posterior end of the ligament. Here, as shown in Fig. 4B, the inner lobes (FI) are fused, forming a ridge of tissue lying between the middle lobes $(M)$. The periostracum $(P)$ is secreted from the groove between the middle and outer (O) lobes. Anteriorly (Fig. 3B), the periostracum is present as a single delicate thread and the middle lobe $(M)$ is represented by a median ridge of tissue between the two outer lobes. This appearance in transverse section of a single periostracal thread and of a single middle lobe does not represent a fusion of the periostracal grooves and of the middle mantle lobes. As will be seen from Fig. 4A, the transverse section represented in Fig. 3 B passes through the periostracal groove (PG) and the middle lobe (M) of the mantle edge at the depth of the posterior embayment between the 

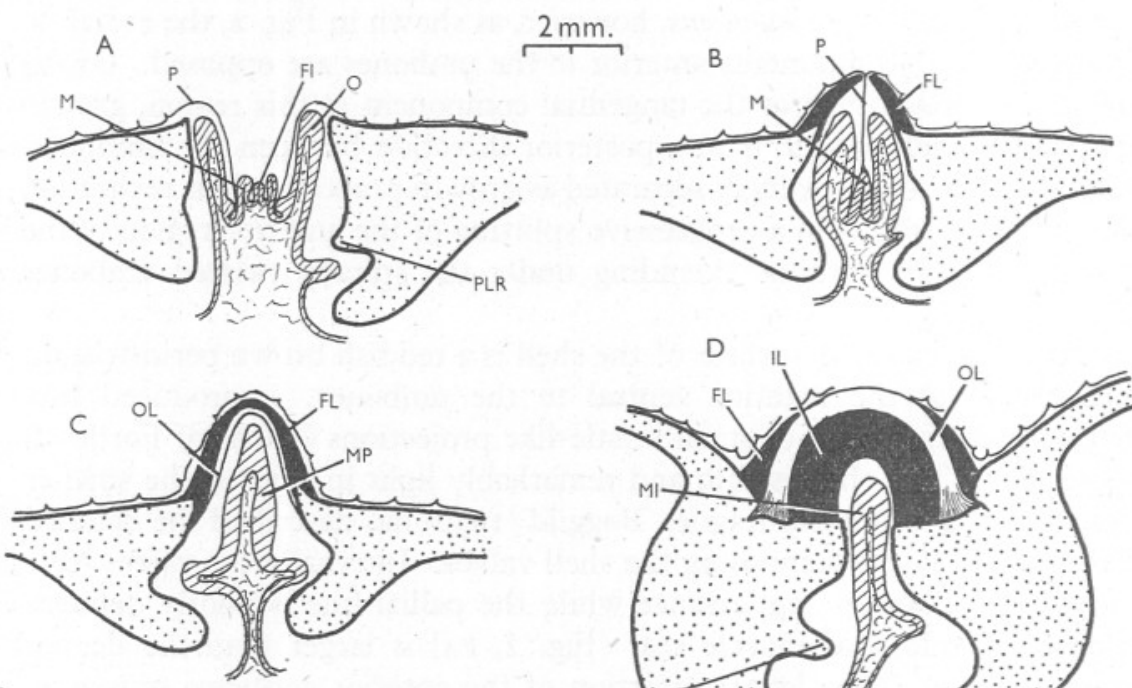

Left
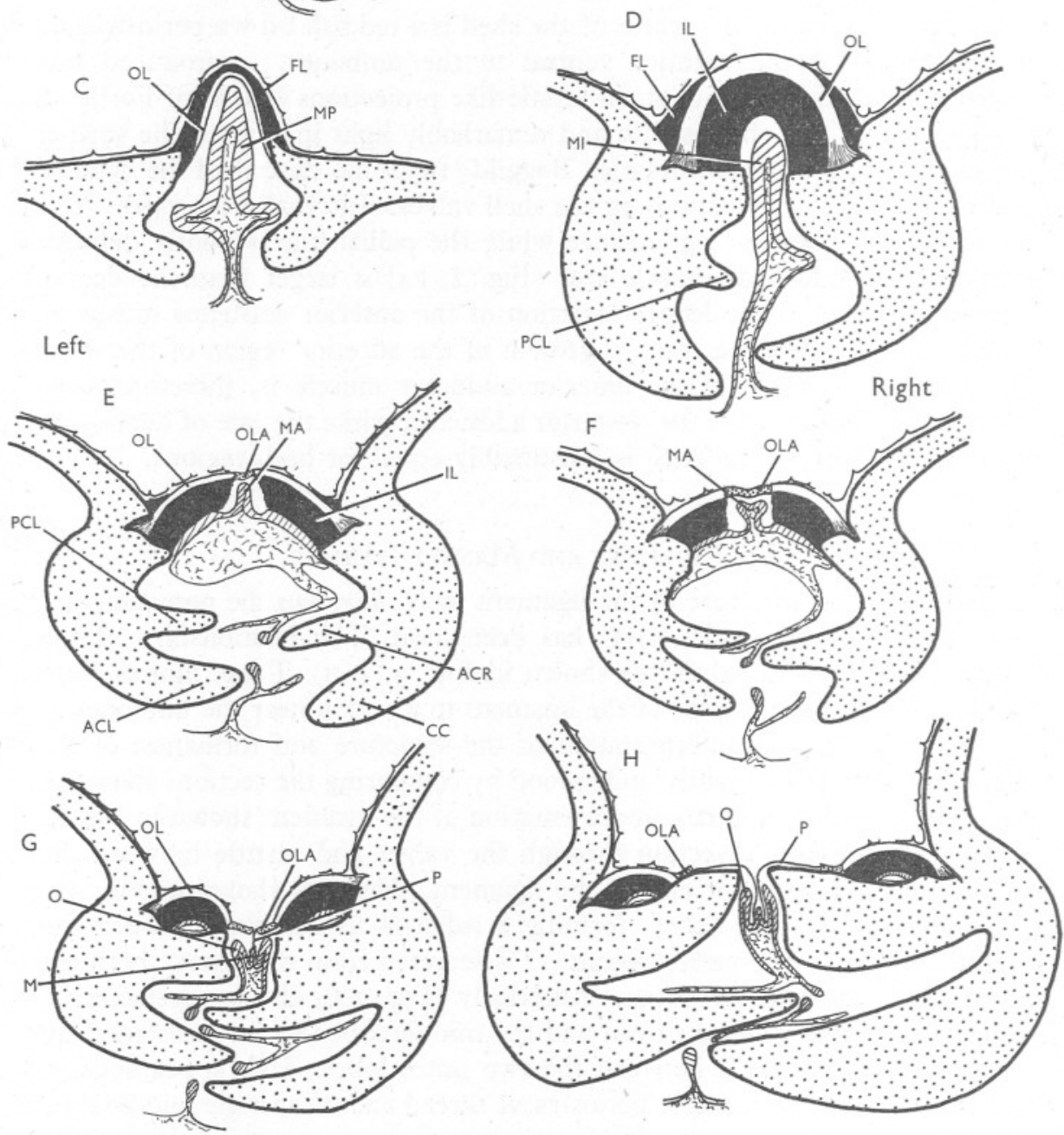

Fig. 3. G. humanus, diagrams representing transverse sections through the ligament, valves and mantle. The positions of the sections are shown in Fig. 2. ACL, left anterior cardinal tooth; FI, fused inner lobes; FL, fusion layer; IL, inner layer; $M$, middle lobe; MA, mantle edge anterior to the mantle isthmus; MI, mantle isthmus; MP, mantle edge posterior to the mantle isthmus; o, outer lobe; OL, 'outer' layer; OLA, anterior 'outer' layer; P, periostracum; PCL, left posterior cardinal tooth. Other lettering as before. 
two lateral lobes of the mantle. The outer lobes secrete on each side a flange of conchyolin-like material (FL) attached laterally to the edges of the valves. Anteriorly (Fig. 3C), this secretion forms an inverted V-structure linking the two valves. This fusion layer (Owen et al. 1953) is secreted by the fused outer lobes posterior to the mantle isthmus (Fig. 4, FO). At the posterior end of the mantle isthmus, the mantle edge (Fig. $3 \mathrm{C}, \mathrm{MP}$ ) secretes additional layers of horny material (OL) on the inner surface of the fusion layer. This horny material is the 'outer' layer of the ligament (Fig. 4B). Fig. 3D represents

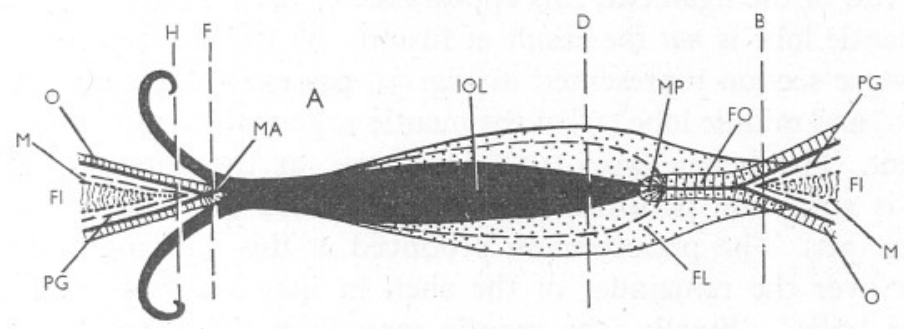

Ant.

Post.

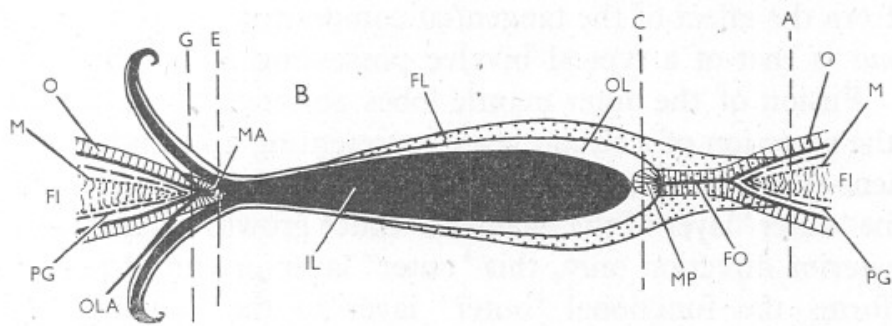

Fig. 4. G. humanus, diagrammatic representation of the ligament, A, viewed dorsally, B, horizontal longitudinal section. FO, fused outer lobes; IOL, 'outer' and inner layers of ligament; PG, periostracal groove. Other lettering as before. The letters A-H refer to the sections drawn in Fig. 3.

a section through the mantle isthmus (MI) and shows the bulky inner layer (IL) secreted by the epithelium of the isthmus and characteristic of the ligament of most lamellibranchs (Owen et al. 1953).

Although the sections shown in Fig. 3(A-D) were taken from different regions of the same specimen they could be interpreted equally well as having been taken, a constant distance posterior to the umbones, from different specimens at various stages of growth. Fig. $3 \mathrm{~A}$ would then represent the youngest growth stage and Fig. 3D the oldest growth stage. During growth, the mantle isthmus extends posteriorly below the periostracum, fusion layer and 'outer' layer. In the region of the isthmus, the ligament therefore consists of a superficial periostracum, a fusion layer, an 'outer' layer and a bulky inner layer (Figs. 3D and 4B). The fusion layer becomes split in the mid-line above the posterior region of the inner layer (Fig. 4A). 
The anterior region of the ligament in G. humanus is progressively split along the mid-line as growth proceeds. This split first appears in the inner layers but, as shown in Fig. 3 E, soon extends to the outer layers of the ligament. A ridge of epithelium, representing the edge of the mantle anterior to the mantle isthmus (Fig. 4B, MA), secretes a layer of horny material (OLA) connecting the split portions of the 'outer' layer. Anteriorly (Fig. $3 \mathrm{G}$ ), the periostracum $(P)$ is present as a single thread while the middle lobe $(M)$ is represented by a median ridge of tissue between the outer lobes (o). As at the posterior end of the ligament, this appearance of the periostracum and of the middle mantle lobe is not the result of fusion. As will be seen from Fig. 4B, the transverse section represented in Fig. 3G passes through the periostracal groove $(\mathrm{PG})$ and middle lobe $(\mathrm{M})$ of the mantle edge at the depth of the anterior embayment. The horny layer (OLA) produced at the anterior end of the ligament is split, the periostracum being attached laterally to the broken edges (Fig. $3 \mathrm{G}$ ). The periostracum produced at this anterior region differs from that over the remainder of the shell in that it is not produced into bristles or 'cilia'. Finally, the mantle margin at the anterior end of the ligament has the appearance shown in Fig. $3 \mathrm{~A}$.

Apart from the effect of the tangential component upon it, the ligament in G. humanus is that of a typical bivalve possessing an external opisthodetic ligament. Fusion of the outer mantle lobes posterior to the mantle isthmus involves the secretion of a fusion layer representing a secondary extension of the ligament (Owen et al., 1953). The mantle edge posterior to the isthmus secretes the 'outer' layer of the ligament. Since growth of the mantle isthmus is in a posterior direction only, this 'outer' layer produced posterior to the isthmus forms the functional 'outer' layer of the ligament. The horny material (OLA) or 'outer' layer secreted by the mantle edge (MA) anterior to the isthmus is progressively split as growth proceeds due to the effect of the tangential component on the mantle/shell margins. A fusion layer similar to that produced by the fused outer lobes posterior to the mantle isthmus is not produced anteriorly, there being no fusion of the outer marginal lobes in the anterior embayment of the mantle. As with the splitting of the anterior region of the ligament, this absence of fusion of the outer lobes is a result of the effect of the tangential component on the mantle margins.

The structure of the ligament in G. humanus is similar to that described by Trueman (1949, 1950) for Tellina tenuis and Mytilus edulis. The fusion layer is probably comparable to Trueman's layer I $a$. In Glossus humanus, as in Mytilus, this layer becomes split in the mid-line above the posterior region of the inner layer of the ligament. There can be no doubt that the periostracum in G. humanus is continuous over the external surface of the ligament. Observation was aided by the presence of the characteristic bristles which serve to differentiate the periostracum from the underlying layers. Indeed, the only region of the shell not covered by periostracum appears to be the 'outer' 
layer secreted by the mantle edge anterior to the isthmus. Over the posterior region of the ligament the periostracum is, however, often worn and only patches are left adhering to the outer surface.

\section{HABIT AND HABITAT}

G. humanus has been described as an inhabitant of sand, sandy-mud and mud. The specimens from the Clyde Sea Area were found in very soft mud in company with such other typical mud-dwellers as Brissopsis lyrifera, Nucula sulcata and Abra alba. Occasional specimens of Aporrhais serresiana, a typical soft-mud dweller (Yonge, I937) were also found. Colonies of Perigonimus sp. were often found growing on the shells of older specimens near the posterior margins of the valves. On one extremely large specimen obtained in an otter trawl from Loch Sween and measuring II $\cdot 0 \mathrm{~cm}$ long by $10.2 \mathrm{~cm}$ deep, there were a number of small anemones attached near the posterior margins of the valves.

The species is probably restricted to a soft muddy substratum since the inflated form of the shell and the relatively weak musculature of the foot would render it unfit for life in firmer substrates. Glossus humanus is a suspension feeder and in soft substrates there is danger of sinking beneath the surface with subsequent fouling of the short siphons. The light weight of the shell is probably associated with the habitat. It is interesting to compare G. humanus with the similar-sized bivalve Arctica (Cyprina) islandica, an inhabitant of coarser and firmer substrates of sand and sandy mud. In this species, the spiral angle is low and the shell much more compressed laterally. The shell is thick and heavy and the foot large and extremely powerful. Specimens of Glossus humanus and Arctica islandica were placed on sand in an aquarium tank. The specimens of $A$. islandica found little difficulty in burrowing rapidly into the sand until their siphons were flush with the surface. One specimen of Glossus humanus, after an interval of $\mathrm{I} 2 \mathrm{hr}$., did succeed in covering approximately a third of the shell; the others remained more or less on the surface of the sand. The most critical feature restricting the animal to a soft type of substrate may well be the poor elastic properties of the hinge ligament. According to information received personally from E. R. Trueman, the opening thrust of the ligament of Arctica islandica is about eight times that of Glossus humanus. Occasional small specimens of G. humanus were found in the Clyde Sea Area in somewhat firmer muds than those off the coast of Arran but medium or large specimens were never obtained from these areas. This could be explained by the fact that the elastic properties of the ligament decrease with increase in size of the animal. In young specimens, cutting of the muscle attachments causes the valves to gape, but in older specimens the ligament appears to produce no opening thrust, the valves remaining closed when the muscles are cut. 
Reports on vertical distribution are confused. Jeffreys (I876) records the fry and very young as ranging from depths of 50 to 1785 fathoms $(9 \mathrm{I}-3265 \mathrm{~m}$.) in the North Atlantic and from 40 to 1456 fathoms $(73-2663 \mathrm{~m}$.) in the Mediterranean. Nicol (I95I) points out that Jeffreys misidentified species of Kelliella for the young of Glossus humanus and that the latter probably range from 5 to $150 \mathrm{~m}$. The specimens from the Clyde Sea Area were obtained from depths of more than $50 \mathrm{~m}$.

The foot of G. humanus possesses a well-developed byssus gland and groove but threads were observed only in the younger specimens. The foot is capable of considerable extension (Fig. 5, F) but appears not to be much used in the larger forms. The siphons are short and surrounded by a common sheath of some ninety or more tentacles; the inhalant siphon is surrounded by a second inner sheath of approximately fifty tentacles. The siphons are flecked with reddish brown and opaque white areas, and their musculature appears to be more or less identical with those of Aloidis as described by Yonge (I946). The animal is extremely sensitive to any form of vibration. Specimens placed in a jar withdrew their siphons when a hand was placed lightly on the bench on which the jar stood. This sensitivity is further evidence that Glossus humanus normally inhabits quiet waters.

\section{The Mantle}

The mantle edge consists of the usual three lobes, the innermost being fused except in the regions of the pedal gape and the siphons (Fig. 5). The mantle is thin and delicate, the inner epithelium being ciliated and concerned with the elimination of waste material from the mantle cavity. The general trend of particles affected by this ciliation is from anterior to posterior toward the inhalant siphon. The main tract is from a region near the labial palps, ventrally and posteriorly to the region of fusion of the inner mantle lobes at the posterior end of the pedal gape (PG), and then posteriorly to the inhalant siphon (I). An interesting and apparently unique feature is that the pseudofaeces do not collect in a single mass at the base of the inhalant siphon but accumulate laterally on the side walls of the siphon (PS).

Mucus is supplied by glands distributed among the cells of the inner epithelial layer of the mantle. In addition, there are, in the connective tissue immediately beneath the epithelial-layer, numerous spaces filled with a granular material. These spaces extend in a broad band dorsal to the ventral ciliated tract of the mantle from a region near the anterior adductor muscle to the posteriorly situated siphons. The contents are discharged on to the inner mantle surface through narrow pores extending between the epithelial cells. The nature of this substance is somewhat obscure. It gives a positive reaction with Schiff's leucofuchsin after oxidation with periodic acid. This indicates a polysaccharide component. Staining for glycogen with full controls gives 
negative results, as does the Toluidine Blue metachromatic reaction for chondroitin and mucoitin sulphuric acids. Alcian Blue $8 \mathrm{GS}$ (Steedman, 1950) - a mucin stain-fails to stain it. Nevertheless, it seems probably to be some form of mucin-like substance, using the term mucin in a physical sense.

\section{Organs in the Mantle Cavity}

Both anterior and posterior adductor muscles are well developed, the anterior being about half the size of the posterior (Fig. 5). The pedal muscles are delicate with the anterior somewhat stouter than the posterior (PR). The labial palps are well developed and function in the usual manner (LP).

The ctenidia are heterorhabdic and deeply plicate with the inner demibranchs somewhat deeper than the outer (Fig. 5). There is an extensive supraaxial region (SA) and both inner (ID) and outer (OD) demibranchs curve inward over the visceral mass. Cuticular fusion of the type described by Atkins $(1937 b)$ connects the inner lamellae of the inner demibranchs of the two ctenidia, the inner lamellae of the inner demibranchs and the visceral mass, and the outer lamellae of the outer demibranchs and the mantle. Where the visceral mass passes between the two inner demibranchs posteriorly, there is a short region where the inner lamellae are not fused to the visceral mass or to one another. As in Aloidis (Yonge, 1946), a direct connexion can be established between the inhalant chamber below and the exhalant chamber above.

As shown in Fig. 5, material is carried by the frontal cilia to the free edges on both sides of the inner demibranch, on the outer surface of the outer demibranch, and on the ventral half of the inner surface of the outer demibranch. A narrow marginal groove is present at the free edges of both the inner and outer demibranchs. The frontal cilia of the dorsal region of the inner lamella of the outer demibranch convey material to the ctenidial axis where there is a strong anteriorly directed current. Material from the inner marginal groove passes directly between the palps to the mouth while material from the outer marginal groove and the axis reaches the mouth by way of the distal oral groove.

As noted by Ridewood (I903), the plications of the gill are not evenly spaced but are arranged in pairs. The inter-lamellar septa are alternately high and low so that, in the dorsal regions of the demibranchs, one principal filament is associated with an inter-lamellar septa while the next is not. Lateral cilia are well developed and produce a powerful inhalant current. Large eu-laterofrontal cilia, $35 \mu$ in length, guard the inter-filamentar spaces, and there are smaller pro-latero-frontal cilia between them and the frontal cilia. The ciliation is similar on all filaments including the principal filaments.

Despite the deep plication of the gills, the walls of the marginal grooves are not scalloped since the plicae, as in Solecurtus, Cardium and Lutraria (Atkins, I 937 a), tend to smooth out toward the free margins. Examination of the free 
margins of the gill under the microscope show what appear to be clear peglike processes, some Io $\mu$ long, projecting from the filaments on either side of the marginal groove. Staining with Heidenhain's haematoxylin indicates that they are made up of tufts of cilia comparable to the 'sensory' tufts of cilia occurring on the frontal surfaces of the filaments of the gills in a number of species (Atkins, I936). In Glossus humanus, they are largely restricted to the free margins of the posterior regions of the gills.

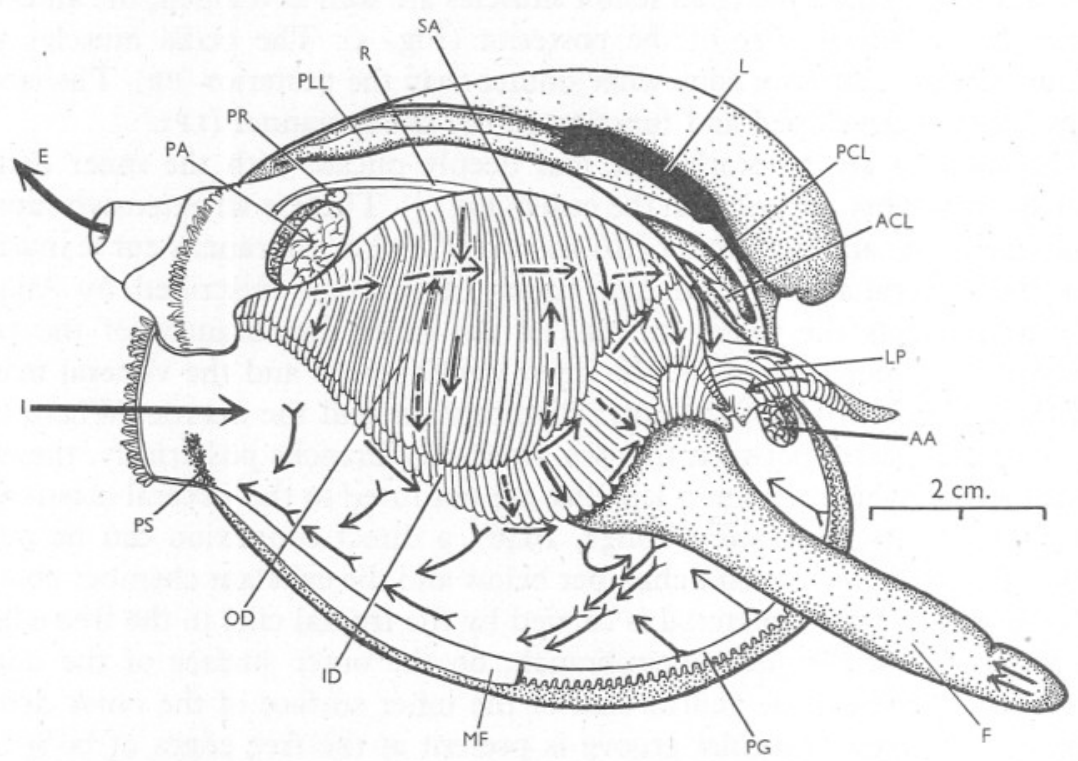

Fig. 5. G. humanus, organs of the mantle cavity exposed after removal of the right shell valve and mantle lobe. F, foot; ID, inner demibranch; LP, labial palp; MF, region of fusion of inner marginal lobes; OD, outer demibranch; PG, pedal gape; PLL, left posterior lateral tooth; PR, posterior retractor muscle; PS, pseudofaeces; R, rectum; SA, supra-axial region. Large arrows indicate inhalant (I) and exhalant (E) currents; small arrows, ciliary currents on exposed surfaces; broken arrows, currents on inner surfaces of demibranchs; feathered arrows, rejection currents. Other lettering as before.

Despite the muddy type of substrate, guard cilia (Atkins, I937a) are not present at the edges of the marginal grooves. As in many lamellibranchs, coarse cirrus-like cilia, 40-50 $\mu$ long, occur along the free margins of both the inner and outer demibranchs. Similar cilia occur scattered over the frontal surfaces of the filaments and on the surface of the ctenidial axis. Those present on the filaments attain a length of some $70 \mu$ while those of the axis reach the surprising length of $\mathrm{I} 30 \mu$. Presumably, as suggested by Yonge (I946), they are concerned with the movement of large particles and masses.

Atkins (I937a) has emphasized the part played by the gills of most lamellibranchs in the sorting of material. The narrow marginal grooves in G. humanus ensure that only small particles are conveyed anteriorly toward the palps and mouth. Large particles and masses fail to enter the marginal grooves and soon 
fall off the gill edge on to the rejectory tracts of the mantle surface. The paired arrangement of the plicae may also help in the rejection of material. Contraction of the gill musculature results in the apposition of adjacent plicae; presumably this would happen if the inhalant current contained a considerable amount of suspended matter. With the gill in this condition, particles removed from the water tend to concentrate on the almost flat portions of the lamellae between the pairs of closely approximated plicae; they travel ventrally toward the free edges. The presentation of these 'concentrated' masses of particles to the narrow marginal grooves increases the possibility of their rejection on to the ciliated surface of the mantle.

The gills of $G$. humanus, however, cannot be regarded as adapted for dealing with water containing large amounts of sediment. The deep plication may be considered primarily as a means of increasing the collecting surfaces of the ctenidia; it will also increase the power of the inhalant current. Thus, despite the muddy nature of the substrate to which the species is almost certainly restricted, the gills in G. humanus appear to be adapted for dealing with large volumes of water containing relatively small quantities of suspended material. Such conditions are likely to occur in water where there is little or no disturbance of the bottom deposits.

\section{The Alimentary Canal}

The mouth, situated between the paired palps, leads into the oesophagus which is compressed dorso-ventrally and richly supplied with mucous glands. It enters the antero-dorsal region of the stomach, which lies in the dorsal region of the, visceral mass and is enclosed antero-laterally and ventrally by the digestive diverticula. Leaving the stomach posteriorly and ventrally is the combined style sac and mid-gut, partially separated from one another by the major and minor typhlosoles. The style sac is curved and extends ventrally to the junction of the foot and visceral mass. Within the visceral mass, and anterior to the style sac, the mid-gut is thrown into three loops. The hind-gut ascends dorsally, posterior to the style sac, to penetrate the pericardium and pass through the ventricle of the heart. A well-developed aortic bulb extends posteriorly from the ventricle to the posterior adductor muscle. The hind-gut lies within this aortic bulb attached to the mid-dorsal wall. Finally, the hindgut passes over the posterior adductor to open at the anus near the exhalant siphon.

\section{The Morphology of the Stomach}

The external form of the stomach in G. humanus is shown in Fig. 6. Dissections were carried out on living specimens and the course of the ciliary currents followed by means of fine carborundum powder and carmine. No matter how carefully the stomach was opened, some part of the internal anatomy was invariably lost or distorted. The drawing of the stomach is 
therefore the result of observations on a number of specimens, the stomachs having been opened by a variety of incisions (Fig. 7). As far as possible the nomenclature introduced by Graham (I949) has been used. It is proposed, however, as suggested by Purchon (I953), to describe the 'right half' and 'left half' of the caecum as the 'right caecum' and 'left caecum' respectively.

The stomach in G. humanus may be conveniently divided into three regions; a globular posterior region, an anterior receiving region, and a dorsal hood. The dorsal hood (Fig. 6, DH) extends anteriorly over the posterior part of the stomach and ends blindly on the left dorsal side as a small coiled tube

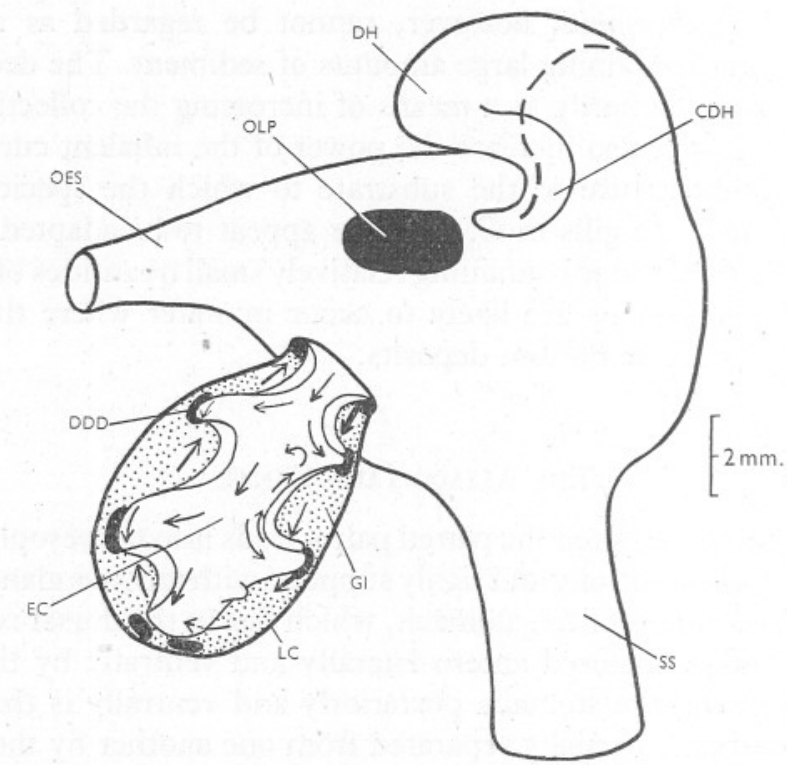

Fig. 6. G. humanus, diagram of the external appearance of the stomach. CDH, coiled region of dorsal hood; DDD, opening of duct from digestive diverticula; $\mathrm{DH}$, dorsal hood; EC, extension of typhlosole within left caecum; GI, intestinal groove; LC, left caecum cut open; OES, oesophagus; OLP, opening of left pouch; sS, combined style sac and mid-gut. Arrows indicate ciliary currents within the left caecum.

$(\mathrm{CDH})$. The greater part of the stomach consists of the posterior globular region (Fig. 7). Leaving this region ventrally is the combined style sac and mid-gut (Ss). The minor typhlosole $\left(\mathrm{T}_{2}\right)$ ends at the junction of the style sac with the stomach while the major typhlosole $\left(\mathrm{T}_{1}\right)$ extends as a flap-like structure anteriorly across the floor of the stomach. As in the majority of Eulamellibranchia, it is continued into the right (ORC) and left (OLC) caeca (Graham, I949) to form broad tongue-shaped structures (Fig. 6, EC). Continuous with the mid-gut and following the course of the major typhlosole is the intestinal groove (Fig. 7, GI). The posterior sorting area (SAP) is well developed, extending dorsally over the right wall of the stomach and on to the right wall of 
the dorsal hood. The posterior margin of the sorting area is formed by a welldeveloped fold (PF) while the anterior margin is formed by the rejection groove (RG) which drains into the intestinal groove on the floor of the stomach. The anterior margin of the rejection groove is formed by a second fold bearing a number of small parallel ridges $(\mathrm{AF})$.

The openings of the ducts to the digestive diverticula are to a considerable extent concentrated within the right and left caeca. The ducts of the right dorsal regions of the diverticula open independently on the right dorsal wall of the stomach (RD) while those of the left dorsal regions open into the left pouch. The pouch opens into the stomach by a single large aperture (OLP) near the gastric shield (GS). The gastric shield consists of a thickened convex portion between the apertures of the coiled region of the dorsal hood $(\mathrm{OCH})$ and the left pouch (OLP) and a larger wing-like expansion extending over most of the left posterior wall of the stomach and the left ventral wall of the hood. A spur-like extension of the shield projects into each of the openings helping to maintain the shield firmly in position.

The anterior receiving region of the stomach is little more than an expansion of the oesophagus (OES). The entrance of the oesophagus into the stomach is marked by a circular groove (CG) which is continued posteriorly over the roof of the stomach (DG). This dorsal groove curves over the ventral lip of the hood, between the thickened portion of the gastric shield and the anterior fold, to terminate on the ventral floor of the hood (Fig. 8).

The posterior sorting area, together with the rejection groove and bounded by the anterior and posterior folds, extends on to the right wall of the dorsal hood (Fig. 8, SAP). The anterior fold curves round on to the antero-ventral face while the posterior fold forms a crest over the mid-dorsal line of the hood. Both anterior and posterior folds terminate within the coiled portion of the hood, the anterior in a curious circular protuberance. Extending over the roof of the hood to the left of the posterior fold is a powerfully ciliated acceptance tract which is continued ventrally over the posterior wall of the stomach (AT). Over the left wall of the hood and extending to the margin of the gastric shield is a series of poorly developed folds.

\section{The Functioning of the Stomach}

That in the Lamellibranchia both intracellular and extracellular digestion occur is generally agreed. The crystalline style is the source of certain extracellular enzymes which are liberated into the stomach by the dissolution of the style (Yonge, I925). Intracellular digestion takes place within the cells of the digestive diverticula (Yonge, I926a). With these facts it should be possible to estimate some of the more important mechanical requirements of the lamellibranch stomach. For the efficient utilization of the extracellular enzymes the ingested particles should be brought into intimate contact with the crystalline style. Secondly, for intracellular digestion, it is essential that 
fine particles be presented to the digestive diverticula. This may be achieved either by an effective sorting mechanism capable of selecting suitable particles or by the ingested particles undergoing a process of trituration. Finally, the waste materials from the digestive diverticula, consisting of solid excretory products and rejected particles, should be prevented from returning to the gastric cavity.

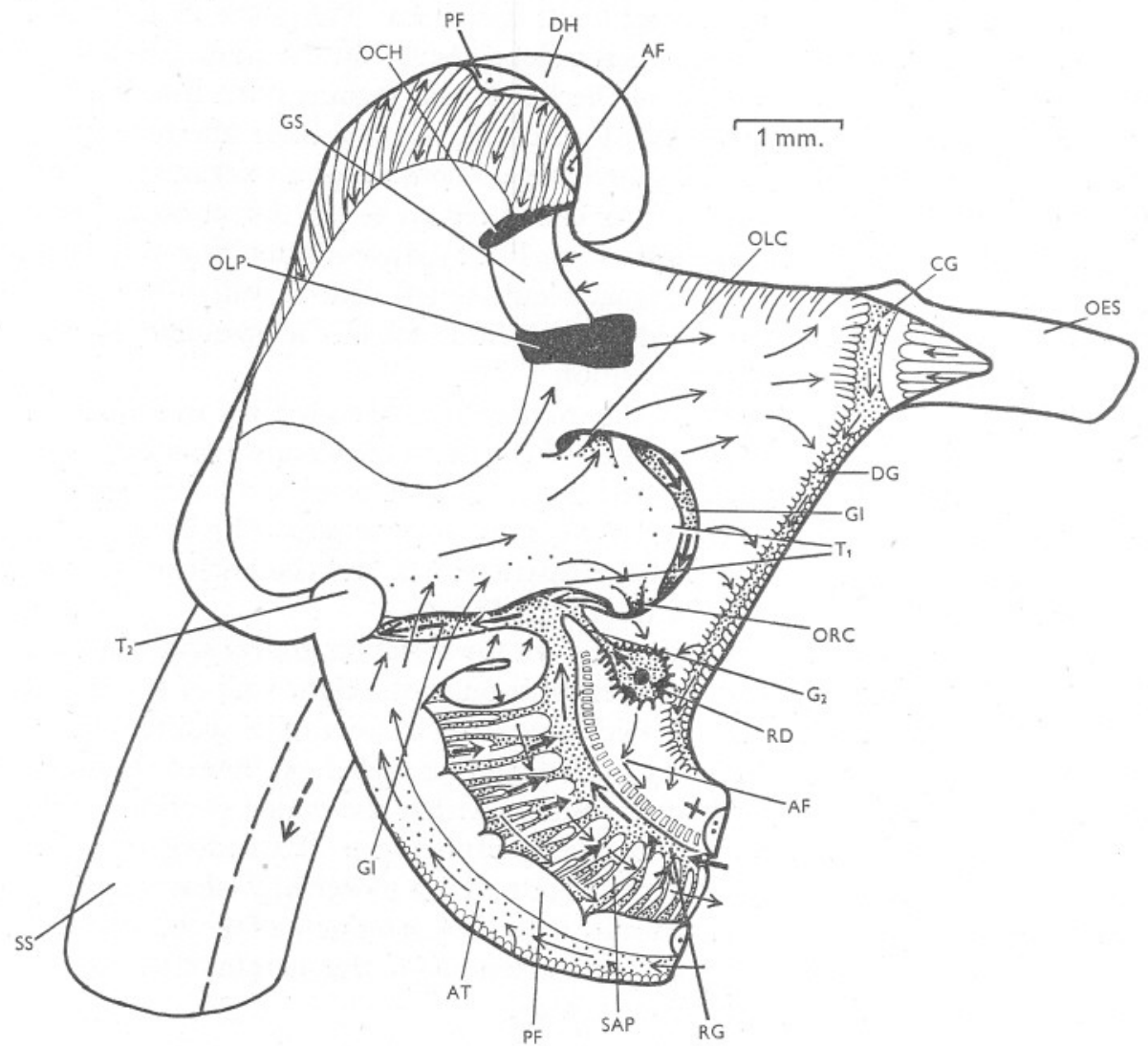

Fig. 7. G. humanus, stomach opened by a dorsal and posterior incision and the right wall deflected ventrally. AF, anterior fold; AT, acceptance tract; CG, circular groove; DG, dorsal groove; $G S$, gastric shield; $G_{2}$, rejection groove from isolated ducts of right side; $\mathrm{OCH}$, opening of coiled region of dorsal hood; OLC, opening of left caecum; oRC, opening of right caecum; $\mathrm{PF}$, posterior fold; $\mathrm{RD}$, opening of isolated ducts of right side; $\mathrm{RG}$, rejection groove; SAP, posterior sorting area; $\mathrm{T}_{1}$, major typhlosole; $\mathrm{T}_{2}$, minor typhlosole. Other lettering as before. The arrows indicate the direction of ciliary currents.

To understand the functioning of the stomach it is necessary to realize that the crystalline style rotates. Unfortunately the style has not been observed revolving in G. humanus, but investigation of the cilia of the style sac suggests that it revolves in a clockwise direction when viewed from above. This is 
supported by the observations of workers who have viewed the rotation of the style in other species; Nelson (I9I8) in Modiolus and Anodonta; Yonge (I926b) in the spat of Ostrea edulis; Yonge (I949) in Tellina tenuis; Yonge (I95I $a$ ) in Sphenia binghami; Yonge (I95I $b$ ) in Cryptomya californica. The statement by Yonge (I95 $b$ ) that the style in Cryptomya rotated in an anticlockwise direction when viewed from the anterior end was printed in error (personal communication).

In Glossus humanus particles entering the stomach from the oesophagus are conveyed dorsally by the cilia of the circular groove and then directed posteriorly by the cilia of the dorsal groove (Fig. 7). At the ventral lip of the dorsal hood (the region marked $\mathrm{x}$ ) the particles are directed against the ridges of the anterior fold (AF). Here, at least when the stomach has been opened for observation, the particles embedded in mucus collect and remain stationary. In the intact stomach the revolving crystalline style may reasonably be presumed to brush these particles on to the ridged surface of the posterior sorting area (SAP). The ciliary mechanisms of the grooves and ridges of this area exercise a quantitative selection. The heavier particles are carried by the cilia of the grooves to the rejection groove (RG) and so to the mid-gut by way of the intestinal groove (GI). The lighter particles are carried dorsally, being thrown from crest to crest across the ridges. Thus, only the finest particles are retained and reach the distal regions of the dorsal hood (Fig. 8). Within the dorsal hood they are directed to the edge of the gastric shield and included in the revolving mass at the head of the crystalline style. The style is relatively delicate and almost certainly incapable of causing any effective trituration of particles.

The acceptance tract (AT) conveys particles from the head of the crystalline style over the roof of the dorsal hood and ventrally over the posterior wall of the stomach (Fig. 7). Where this current has been described in previous accounts it has generally been considered as supplying particles to the mid-gut. In $G$. humanus, however, this current serves to carry particles on to the floor of the stomach. The entrance of particles into the mid-gut is prevented by the flap-like structure of the major typhlosole which extends over the intestinal groove. The currents on the floor of the stomach are directed towards the openings of the left pouch (OLP), the left (OLC) and right (ORC) caeca and the isolated ducts of the right side (RD). Within the right and left caeca the ciliary currents over the extensions of the major typhlosole direct particles towards the openings of the ducts into the digestive diverticula (Fig. 6, DDD).

The material carried by the acceptance tract should therefore consist of fine particles which have previously been in contact with the crystalline style. The pattern of ciliary activity within the dorsal hood is shown in Fig. 8. It was at first thought that the poorly developed folds over the left wall of the hood might constitute a sorting area. Detailed investigation of the ciliary currents did not reveal any selective action. The currents over the 
ventral regions of the folds direct particles to the edge of the gastric shield while those of the dorsal region direct particles to the acceptance tract. An understanding of the function of these currents can obviously only be obtained through an appreciation of their dynamic relationships with the revolving crystalline style. Fig. 9 shows a simplified diagrammatic representation of the circulation of material within the stomach. The material

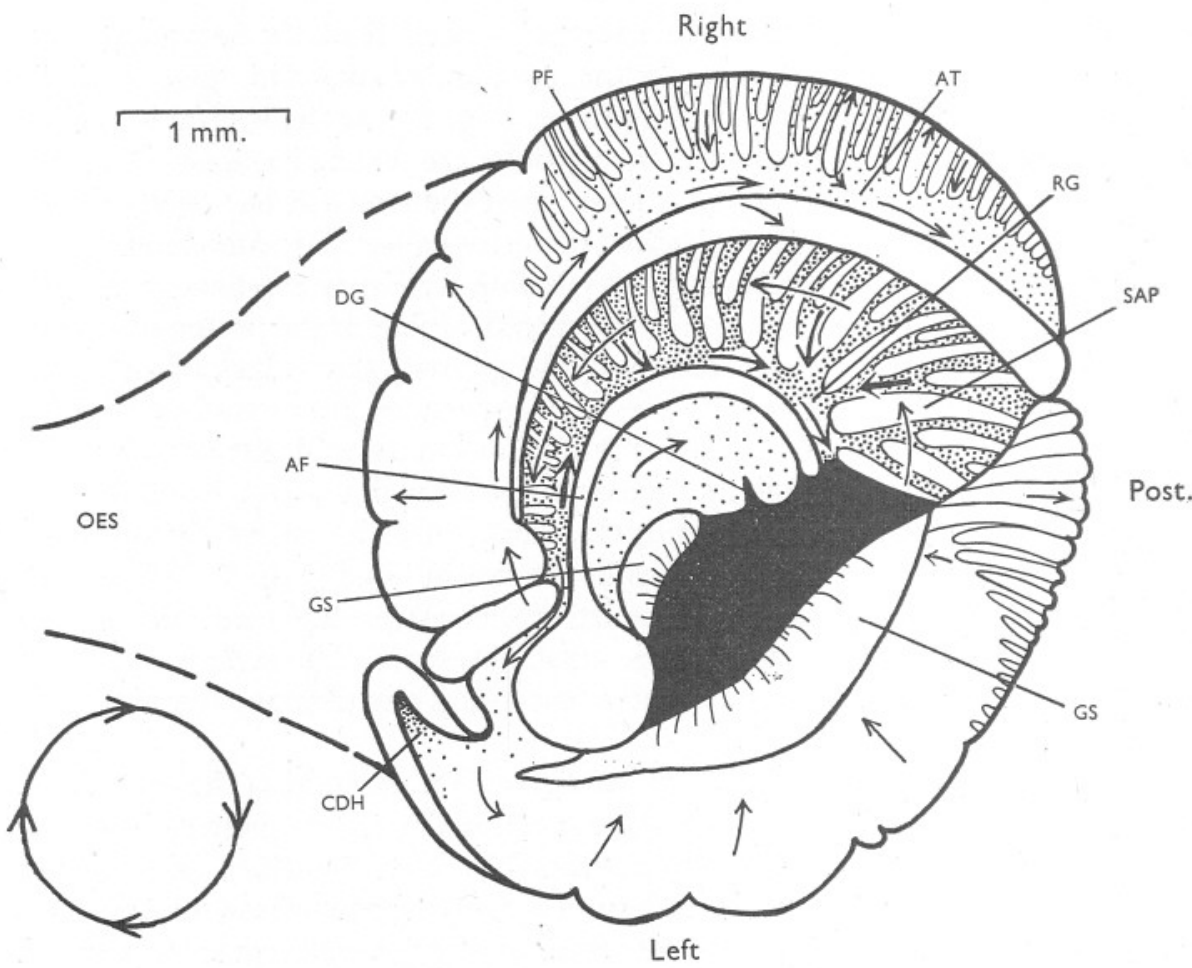

Fig. 8. G, humanus, dorsal hood of stomach opened along the broken line shown in Fig. 6 and viewed dorsally. Lettering as before. Arrows indicate the direction of ciliary currents; the circular arrow indicates the clockwise direction of rotation of the crystalline style when viewed dorsally.

entering from the oesophagus (OES) consists of a mixture of fine and coarse particles. These particles are caught up by the revolving crystalline style (CS) and brushed on to the posterior sorting area. The ciliary currents of the sorting area direct the coarse particles to the mid-gut (MG) by way of the rejection groove $(\mathrm{RG})$ and the intestinal groove $(\mathrm{GI})$. The fine particles are conveyed dorsally. Thus the material being revolved by the crystalline style consists of fine particles at the head of the style passing into a mixture of fine and coarse particles below. The ciliary currents over the dorsal regions of the folds within the dorsal hood therefore convey fine particles from the 
head of the style to the acceptance tract (AT). The currents over the ventral regions of the folds act on a mixture of fine and coarse particles directing them to the edge of the gastric shield and so returning them to the mass around the crystalline style. Some coarse particles may be caught up in the ciliary currents of the acceptance tract as it passes ventrally over the posterior wall of the stomach, although the tract is 'protected' to some extent by the presence of the posterior fold along the right-hand margin. Particles too large to enter the openings of the left pouch, the right and left caeca, and the isolated ducts of the right side are carried anteriorly to join the incoming material and so circulate again. Within the right and left caeca waste products and rejected particles from the ducts of the diverticula are caught up by the ' ciliary currents in the intestinal groove (GI) and conveyed to the mid-gut. Rejected material from the isolated ducts of the right side is conveyed to the intestinal groove by way of the short groove $\mathrm{G}_{2}$ (Fig. 7). The ducts of the diverticula which open within the left pouch return material to the general circulation within the stomach.

Most of the mechanical requirements mentioned earlier are fulfilled in the stomach of G. humanus. The ingested material is subjected to a rigorous sorting which appears to be entirely quantitative and the 'accepted' particles are brought into intimate contact with the style and so with the enzymes released from it. The flap-like major typhlosole isolates the currents in the intestinal groove. This agrees with the description by Graham (I949) of the intestinal groove as the "private pathway of the digestive gland and sorting areas'. In the Eulamellibranchia there appears to be a progressive concentration of the ducts of the diverticula within the right and left caeca. This isolation of the ducts within the caeca may be associated with preventing material rejected by the diverticula from returning to the stomach. Even so, in the majority of the eulamellibranchs, the ducts opening into the left pouch return their waste products to the general circulation within the stomach. This retention of an isolated opening for the left pouch may well be correlated with the need for a firm fixation of the gastric shield. In most species the shield is anchored firmly by the spurs which project into the openings of the left pouch and the coiled region of the dorsal hood.

The stomach in G. humanus is well adapted for dealing rapidly with fine particles and is comparable with the stomachs of the suspension-feeders, Paphia pullastra, Cardium edule and Venus fasciata, as described by Graham (1949). Yonge (1949) has already discussed the reasons for not including Tellina crassa and Solecurtus chamosolen with the above. In both these species of the Tellinacea very coarse particles are taken into the stomach and the style acts as an efficient organ of trituration. Here the possession of an extensive sorting area would be a disadvantage. In fact, in Tellina and Solecurtus, the grooves and ridges of this region are very poorly developed or even absent. 
The efficiency of the stomach mechanism may be judged by a consideration of the paths by which particles are able to enter the mid-gut. The material carried by the intestinal groove is derived from the rejection groove of the posterior sorting area and from the rejectory currents of the digestive diverticula. The rejection groove eliminates those particles rejected by the sorting area. All other particles remain within the gastric cavity until they have been

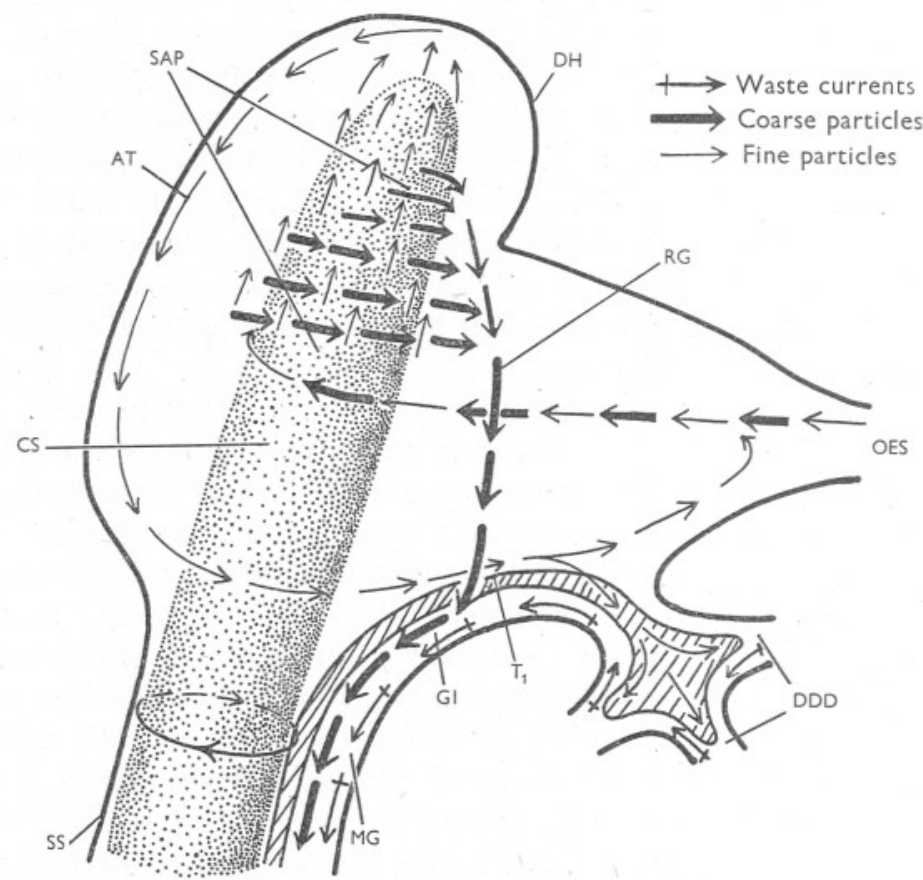

Fig. 9. G. humanus, diagrammatic representation of the circulation of particles within the stomach. Cs, crystalline style; MG, mid-gut; ss, style sac. Other lettering as before. The heavy arrows indicate coarse particles, the light arrows fine particles, and the tailed arrows particles rejected by the ducts from the digestive diverticula.

'presented' either to the ducts of the digestive diverticula within the caeca or to the isolated ducts of the right side. This retention of particles within the stomach is possible because the currents in the intestinal groove are isolated by the flap-like major typhlosole.

\section{REPRODUCTION}

Glossus humanus is unisexual and both the testes and ovaries are white when ripe. The gonads ripen towards the end of August and during September. Artificial fertilization was attempted on 3 September with some success, a small number of apparently normal trochophore larvae being obtained. 
There was little doubt, however, that at this time the ovaries were not fully ripe. Thus, as in Aloidis and Cuspidaria (Yonge, 1946), spawning appears to occur at the end of September. Yonge has suggested that this autumnal spawning may indicate origin in deep water where the highest temperatures occur late in the season.

\section{Discussion}

Glossus humanus is specialized for life in a substratum of very soft mud. The poor elastic properties of the ligament, the inflated form of the shell, and the relatively weak musculature, all suggest a sedentary mode of life within a soft substratum. The siphons are extremely sensitive, and it is unlikely that large quantities of material are normally taken into the pallial cavity. The marginal grooves of the gills are very narrow and convey only fine particles to the labial palps and mouth. These adaptations indicate that G. humanus is normally an inhabitant of fairly deep water where there is little or no disturbance of the bottom deposits. Under such conditions the surrounding water will contain little suspended material. If the animal is to obtain sufficient food large volumes of water must be passed through the gills. Their well-developed plications must be considered primarily as an adaptation for dealing with large volumes of water containing little suspended material. This restriction of the species to deep water is further supported by the late autumnal spawning.

In G. humanus the mechanical functions of the stomach appear to be carried out by ciliary activity aided by the revolving crystalline style. In other Eulamellibranchia, however, the entry of particles into the ducts to the digestive diverticula appears to take place by some means other than cilia (Purchon, 1953). This may also occur to a lesser extent, in G. humanus. The part played by muscular activity in the functioning of the eulamellibranch stomach has, on the whole, been neglected. Patterson (1933) introduced a rubber balloon into the stomach of Schizothoerus nuttallii and so recorded pressure changes there. Slight stomach contractions occurred at the rate of one per minute regardless of the presence or absence of the crystalline style. While the experiment needs to be repeated, it is certainly true that slight changes in pressure within the stomach would aid the entry of particles into the ducts of the diverticula. The particles affected by such small changes in pressure would be those carried anteriorly over the floor of the stomach past the openings of the right and left caeca and the left pouch. These would be the fine particles from the head of the crystalline style which are carried ventrally over the posterior wall of the stomach by the acceptance tract.

Recently there has been much discussion regarding digestion in the Lamellibranchia. Mansour \& Zaki (1947) claimed that lipolytic and proteolytic enzymes are secreted into the lumen of the stomach by the digestive diverticula. They suggested that the cells of the diverticula fragment and pass, together with their contained enzymes, into the stomach. George (I952), 
investigating the digestion of fat in lamellibranchs, found that free droplets of neutral fat were hydrolysed in the stomach. Tests on the lipolytic activity of minced styles of several species all gave positive results, while only some species gave positive results in tests on minced digestive diverticula. Nevertheless, it is difficult to associate complete extracellular digestion with the organization of the stomach found in Glossus humanus. Graham (1949) discussed the functioning of the gastropod stomach and indicated the evolutionary trends associated with increased extracellular digestion and the secretory activity of the digestive gland in members of this class. In carnivorous species, such as members of the Stenoglossa, the stomach is little more than a bag where digestion takes place. There is no necessity for a separation of particles on a size basis and sorting areas are not present. The same conditions prevail in many of the pulmonates and opisthobranchs in which extracellular digestion predoninates. This directly contrasts with conditions in the Eulamellibranchia, as exemplified by $G$. humanus, where there is an efficient sorting mechanism selecting particles on the basis of size.

The ciliary currents of the intestinal groove convey to the mid-gut particles discharged from the ducts of the diverticula within the right and left caeca. The flap-like major typhlosole prevents material carried by the intestinal groove from returning to the general circulation within the stomach. In contrast to Mansour \& Zaki (I947), Coe (I947) suggested that the fragmented cells and minute brownish globules passed into the digestive canal from the diverticula were excretory. Morton (I95I), investigating the gastropod family Struthiolariidae, came to the same conclusion. In members of this family fragmentation of the digestive cells results in tiny boluses of excretory matter containing nuclei, phagocytic cells and brown excretory spherules being passed into the gut. Morton emphasized that, although small traces of enzyme were doubtless liberated in this way into the stomach, the fragmented particles were essentially excreta.

Knowledge regarding digestion in the Lamellibranchia is confusing. There seems to be little doubt that extracellular lipases and proteases are present in the gastric cavity, although their source is uncertain. At the same time the complex ciliary mechanisms suggest a considerable degree of intracellular digestion as postulated by Yonge (I926a).

\section{SUMMARY}

Glossus humanus (L.) (Isocardia cor Lam.), a large marine eulamellibranch, occurs in deep water in soft muddy substrates. Restriction of the species to a soft substrate is probably correlated with the inflated form of the shell, the weak musculature of the foot, and the poor elastic properties of the ligament.

Growth of the mantle/shell is the resultant of radial, transverse and tangential components, the normal axis being a turbinate spiral. The anterior 
region of the ligament is progressively split during growth owing to the displacement posteriorly of the secreting surfaces. The relationships of the valves, ligament and mantle isthmus are discussed.

The deeply plicated ctenidia are specialized for dealing with large volumes of water containing little suspended material.

The anatomy and functioning of the stomach is described in detail. There is a complex ciliated mechanism selecting particles on the basis of size. Such a mechanism, it is suggested, must be associated with intracellular digestion. The flap-like major typhlosole prevents material carried by the intestinal groove from returning to the circulation within the stomach, while the retention of an isolated opening for the left pouch is probably correlated with the need for firm fixation of the gastric shield.

Spawning occurs at the end of September.

\section{REFERENCES}

AtKINs, D., I936. On the ciliary mechanisms and interrelationships of lamellibranchs. Part I. Some new observations on sorting mechanisms in certain lamellibranchs. Quart. Fourn. Micr. Sci., Vol. 79, pp. I8I-308.

- I937a. On the ciliary mechanisms and interrelationships of lamellibranchs. Part II. Sorting devices on the gills. Quart. Fourn. Micr. Sci., Vol. 79, pp. 339-73.

- I $937 b$. On the ciliary mechanisms and interrelationships of lamellibranchs. Part IV. Cuticular fusion, with special reference to the fourth aperture in certain lamellibranchs. Quart. Fourn. Micr. Sci., Vol. 79, pp. 423-45.

BøGGILD, O. B., I930. The shell structure of the Mollusks. K. Danske Vidensk. Selsk. Skr., Afd. 9, Raekke 2, pp. 23I-325.

CoE, W. R., I947. Nutrition, growth and sexuality of the pismo clam (Tivela stultorum). Fourn. Exp. Zool., Vol. 104, pp. I-24.

Forbes, E. \& Hanley, S., I853. A History of British Mollusca, and their Shells. Vol. I, London.

GeORGE, W. C., I952. The digestion and absorption of fat in lamellibranchs. Biol. Bull. Woods Hole, Vol. I02, pp. II 8-27.

Graham, A., I949. The molluscan stomach. Trans. Roy. Soc. Edin., Vol. 6I, pp. $737-76$.

JefFreys, G., 1863. British Conchology. Vol. II. London.

I876. New and peculiar Mollusca of the Kellia, Lucina, Cyprina and Corbula families procured in the 'Valorous' Expedition. Ann. Mag. Nat. Hist., Vol. I8, pp. 490-9.

LAMY, E., I920. Revision des Cypricardiacea et des Isocardiacea vivants. Fourn. Conchyliol., T. 64, pp. 259-307.

MANSOUR, K. \& ZAKI, F. G., I947. The digestive diverticula of Unio prasidens as organs of secretion. Proc. Egypt. Acad. Sci., Vol. 2, pp. 38-44.

Morton, J. E., I95I. The ecology and digestive system of the Struthiolariidae (Gastropoda). Quart. Fourn. Micr. Sci., Vol. 92, pp. I-25.

NeLson, T. C., I918. On the origin, nature and function of the crystalline style of lamellibranchs. Fourn. Morph., Vol. 31, pp. 53-III.

Nicol, D., I95I. Recent species of the cyrenoid pelecypod Glossus. Fourn. Wash. Acad. Sci., Vol. 4I, pp. 142-6. 
Owen, G., 1952. Shell-form in the Lamellibranchia. Nature, Vol. I70, pp. I48-9. 1953. The shell in the Lamellibranchia. Quart. Fourn. Micr. Sci. (in the Press).

Owen, G., Trueman, E. R. \& Yonge, C. M., I953. The ligament in the Lamellibranchia. Nature, Vol. I7I, pp. 73-5.

Patterson, T. L., I933. Comparative physiology of the gastric hunger mechanism. Ann. New York Acad. Sci., Vol. 34, pp. 59-272.

PuRCHON, R. D., I953. The structure and function of the British Pholadidae (rockboring Lamellibranchia). Proc. Zool. Soc. Lond. (in the Press).

Ridewood, W. G., I903. On the structure of the gills of the Lamellibranchia. Phil. Trans. Roy. Soc. Lond., B, Vol. I95, pp. 147-284.

Steedman, H. F., I950. Alcian Blue 8GS: A new stain for mucin. Quart. Fourn. Micr. Sci., Vol. 91, pp. 477-9.

Trueman, E. R., I949. The ligament of Tellina tenuis. Proc. Zool. Soc. Lond., Vol. I I9, pp. $717-42$.

- I950. Observations on the ligament of Mytilus edulis. Quart. Fourn. Micr. Sci., Vol. 9I, pp. 225-35.

YONGE, C. M., I925. The hydrogen ion concentration in the gut of certain lamellibranchs and gastropods. Fourn. Mar. Biol. Assoc., Vol. 13, pp. 938-52.

- 1926a. The digestive diverticula in lamellibranchs. Trans. Roy. Soc. Edin., Vol. 54, pp. 703-18.

- 1926b. Structure and physiology of the organs of feeding in Ostrea edulis. Fourn. Mar. Biol. Assoc., Vol. I4, pp. 295-386.

- 1937. The biology of Aporrhais pes-pelecani (L.) and A. serresiana (Mich.), fourn. Mar. Biol. Assoc., Vol. 2I, pp. 687-704.

— 1946. On the habits and adaptations of Aloidis (Corbula) gibba. Fourn. Mar. Biol. Assoc., Vol. 26, pp. 358-76.

- 1949. On the structure and adaptations of the Tellinacea, deposit feeding eulamellibranchs. Phil. Trans. Roy. Soc. Lond., B, Vol. 234, pp. 29-76.

- I95I a. Observations on Sphenia binghami Turton. Fourn. Mar. Biol. Assoc., Vol. 30, pp. 387-92.

- I95I $b$. On the structure and adaptations of Cryptomya californica (Conrad). Univ. Calif. Publ. Zool., Vol. 55, pp. 395-400.

- 1953. The monomyarian condition in the Lamellibranchia. Trans. Roy. Soc. Edin., Vol. 62, pp. 443-78. 